\title{
CHARACTERIZATION AND PERFORMANCE OF LASER ALLOYED COMMERCIAL TOOL STEELS
}

\author{
Mirosław BONEK ${ }^{1}$ \\ ${ }^{1}$ Institute of Engineering Materials and Biomaterials, Silesian University of Technology, 44-100, Gliwice, Poland \\ miroslaw.bonek@polsl.pl
}

Received: 15.01.2013, Accepted: 15.02.2013

doi: $10.5505 /$ pajes.2013.02886

*Corresponding author

\begin{abstract}
The paper presents the effect of alloying with tungsten carbide on properties of the X40CrMoV5-1 steel surface layer, using the high power diode laser (HPDL). Selection of laser operating conditions is discussed, as well as alloying material, and their influence on structure and chemical composition of the steel. Analysis of the process conditions influence on thicknesses of the alloyed layer and heat-affected zone is presented.
\end{abstract}

Keywords: Tool steels, Laser alloying, Surface engineering.

\section{Introduction}

Improvement of surface properties of materials used to date features one of the goals set to the research institutions active in the materials engineering area. Possibilities of increasing the functional properties of the hot-work alloy tool steels by modification of their chemical composition in a conventional way are very limited already. Laser technique features the especially promising tool for solving the contemporary surface engineering problems thanks to the physical properties of the laser beam, making it possible to focus precisely the delivered energy in the form of heat in the surface layer. Moreover, methods which are not based on partial melting of surface alone, but on partial melting with the simultaneous introduction of the alloying elements with high hardness, like carbides, are being employed more and more widely for modification of the surface layer. High cooling rates are obtained in this process and its end result is the fine-grained material with the super-cooled phases [1]-[3]. Material transport in the liquid metal, caused by the surface tension forces, features the main factor deciding development of the alloyed layers. The non-uniform material heating resulting from the laser beam impact causes development of a big surface tension gradient on the surface of the liquid. The force is directed outside from the beam centre where is the highest temperature value to its edge and causes movement of the molten material [4].

Density of power delivered to the surface layer of the processed materials is lower for the more and more often used HPDL type lasers compared to its single mode distribution characteristic for other laser types; however, the energy is distributed more uniformly across the rectangular area of the laser beam focus. Therefore, the HPDL laser is ideally suited for modification of the surface layer of materials. Moreover, employment of the appropriate shielding gases and correctly selected nozzle shape, and its position in respect to the processed material, have the objective to ensure the high quality of weld face and repeatability of the obtained results. The advantages of laser treatment compared to other surface layer modification methods are: high processing rate, possibility to carry out treatment without protective guards, modification of small, arbitrarily selected fragments of the processed surfaces responsible for tools and machine elements life, as well as its material economy [5]-[6].
The goals of this work were: determining the technological conditions for alloying with the tungsten carbide the high speed steel HS6-5-3-8 surface layer using the high power diode laser (HPDL) and determining the relationship between the laser treatment parameters and structure and chemical composition of the steel.

\section{Material and method}

The experiments were made on specimens made from the high speed steel HS6-5-3-8. The chemical composition of the steel is presented in Table 1 . The investigated steel was molten in the electric vacuum furnace at the pressure of about $1 \mathrm{~Pa}$, cast into ingots weighing about $250 \mathrm{~kg}$, and were roughed at the temperature range $1100-900{ }^{\circ} \mathrm{C}$ into the O.D. $75 \mathrm{~mm}$ bars, which were soft annealed. After making by machining the specimens they were heat treated. The specimens were austenitized on the salt bath furnace and tempered in the chamber furnace in the protective atmosphere-argon. The specimens were gradually heated to the austenitizing temperature with the isothermic stops at 650 and $850^{\circ} \mathrm{C}$ for $15 \mathrm{~min}$. Further they were austenized for 30 min at the temperature of $1180{ }^{\circ} \mathrm{C}$ and cooled in hot oil. The specimens were tempered twice after quenching, each time for 2 hours, at the temperature of $560{ }^{\circ} \mathrm{C}$ and next at $545{ }^{\circ} \mathrm{C}$. Surfaces of specimens were sand blasted and machined on magnetic grinder.

Particular attention was paid to prevent development of micro-cracks that might disqualify the specimen from further examination. The tungsten carbide powder was applied on specimens. On specimens surface two parallel grooves, deep for 0.5 of triangular shape (with angle of $45^{\circ}$ ) were machined. The grooves were located along sample axis and distance between them was ca. $1.0 \mathrm{~mm}$. Such prepared grooves were filled with pure WC powder. Properties of the tungsten carbide powder are presented in Table 2 and Figure 1.

Table 1: Chemical composition of the HS6-5-3-8 high speed steel.

\begin{tabular}{cccccccccc}
\hline \multicolumn{8}{c}{ Average mass concentration of elements, \% } \\
\hline $\begin{array}{c}\text { Steel } \\
\text { type }\end{array}$ & $\mathrm{C}$ & $\mathrm{Cr}$ & $\mathrm{W}$ & $\mathrm{Mo}$ & $\mathrm{V}$ & $\mathrm{Co}$ & $\mathrm{S}$ & $\mathrm{P}$ \\
$\begin{array}{c}\text { HS } \\
6-5-3-8\end{array}$ & 1,28 & 4,2 & 6,3 & 5 & 3 & 8,4 & 0,002 & 0,022 \\
\hline
\end{tabular}


Table 2: Selected properties of the tungsten carbide powder.

\begin{tabular}{ccccc}
\hline Powder & $\begin{array}{c}\text { Average } \\
\text { grain } \\
\text { diameter, } \\
\mu \mathrm{m}\end{array}$ & $\begin{array}{c}\text { Melting } \\
\text { temp. }{ }^{\circ} \mathrm{C}\end{array}$ & $\begin{array}{c}\text { Density, } \\
\mathrm{g} / \mathrm{cm}^{3}\end{array}$ & $\begin{array}{c}\text { Hardness, } \\
\mathrm{HV}_{30}\end{array}$ \\
\hline WC & $20-30$ & $\begin{array}{c}2730- \\
2870\end{array}$ & 15.6 & 1550 \\
\hline
\end{tabular}

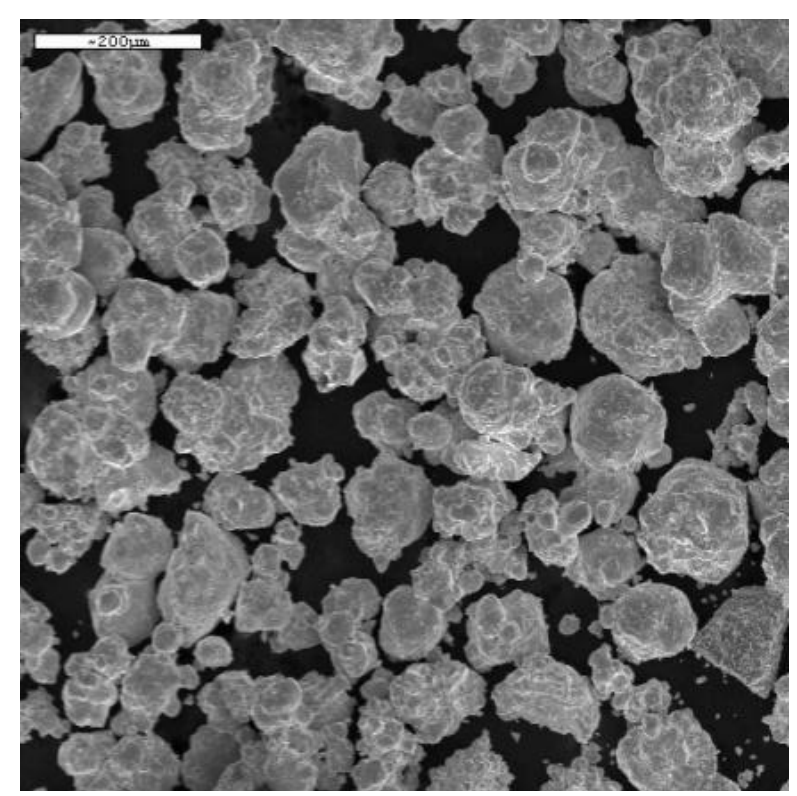

a

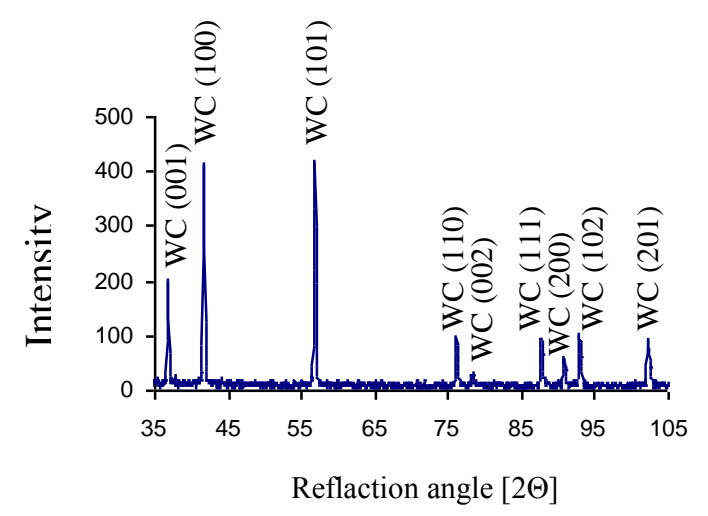

$\mathrm{b}$

Figire 1: a) Ttopography of the WC surface, b) X-ray diffraction of the WC.

It was found out in the preliminary investigations made using the HPDL Rofin DL 020 high power diode laser, with parameters presented in Table 3 and Figure 2, that the maximum feed rate at which the process is stable is $\mathrm{v}=0.5$ $\mathrm{m} / \mathrm{min}$. Therefore all experiments were made at the constant remelting rate, varying the laser beam power in the range from 0.7 to $2.5 \mathrm{~kW}$. At low laser power values, i.e., 0.4 to 0.7 $\mathrm{kW}$, no remelting was observed for powders mentioned above. It was established experimentally that the argon blow-in with the flow rate of $20 \mathrm{l} / \mathrm{min}$ through the $12 \mathrm{~mm}$ circular nozzle oppositely directed in respect to the remelting direction provides full remelting zone protection.

The microsections' surfaces were ground on diamond wheels and next polished using the diamond buffing compounds on Struers equipment. Metallographic examinations of the material structures after laser alloying its surface layer were made on Zeiss LEICA MEF4A light microscope with magnifications from 50 to $1000 x$. The Leica-Qwin computer image analysis system was used for thickness examination of the particular zones of the surface layer. Structure of the developed coatings were examined with SUPRA 25 scanning electron microscope (SEM) equipped with X-ray energy dispersive spectrometer (EDS). The observation were prepared perpendicularly to the cross section of the sample no the each remelted tray.

Table 3: Specification of the HPDL ROFIN DL 020 diode laser.

\begin{tabular}{lr}
\hline \multicolumn{1}{c}{ Wavelength of the laser radiation, $\mathrm{nm}$} & $808 \pm 5$ \\
\hline Maximum output power of the laser beam & 2300 \\
(continuous wave), $\mathrm{W}$ & $100-$ \\
Power range, $\mathrm{W}$ & 2300 \\
Focal length of the laser beam, $\mathrm{mm}$ & $82 / 32$ \\
Laser spot size, $\mathrm{mm}$ & $1.8 \times 6.8$ \\
Power density range in the laser beam focal plane, & $0.8-36.5$ \\
$\mathrm{~kW} / \mathrm{cm}^{2}$ & \\
\hline
\end{tabular}

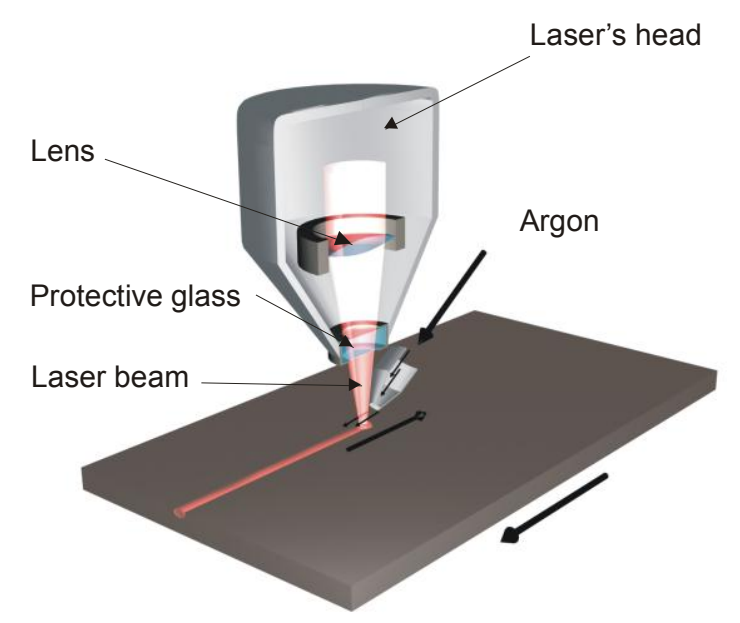

Figire 2: Alloying process of ceramic particles of tool steel using high power diode laser HPDL Rofin DL 020.

\section{Results and Discussion}

Structural examinations consist in comparing the effect of parameters of heat treatment and remelting of the tool steel with the diode laser on the run shape and remelting depth. The gradient layer developed in this way is not free from defects like numerous micro-cracks and cracks, resulting from dissolving WC in the surface layer of the investigated steels, which is shown in Figure 3.

In case of alloying with the tungsten carbide powder, whose melting point is much higher than the melting point of steel, with the initially specified laser power, inundation occurs of the un-molten WC powder grains into the molten steel substrate. Strong circulation of the liquid metal was discovered with rapid solidification after the laser beam has passed, leading to freezing of the structure. It was found out, basing on metallographic examinations, that the structure of the material solidifying after laser fusion is characterized by occurrences of areas with the diversified morphology (Fig. 4a and $4 \mathrm{~b}$ ) connected with crystallization of the steel. Thickness of the gradient layer changes for the laser power sequence is between $1.57 \mathrm{~mm}$ to $1.94 \mathrm{~mm}$ (Figure $4 \mathrm{a}$ and $4 \mathrm{~b}$ ). 


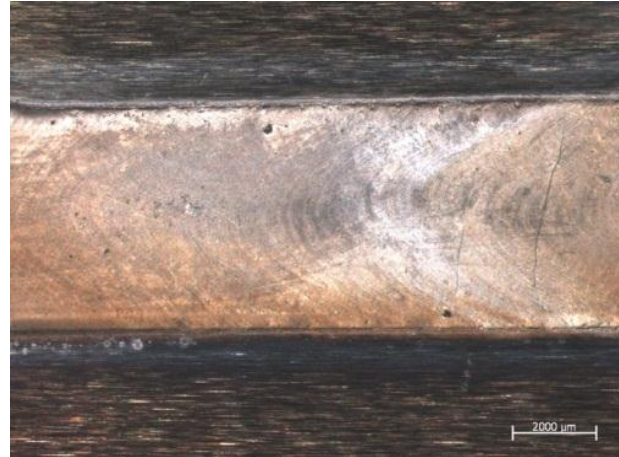

a

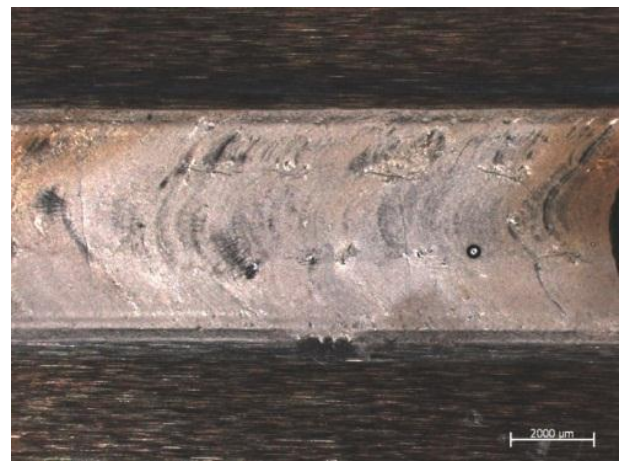

$\mathrm{b}$

Figure 3: Part shape of bead face of the high speed steel surface alloyed with the WC carbide particles with laser power values: a) $1.4 \mathrm{~kW}$, b) $2.1 \mathrm{~kW}$.

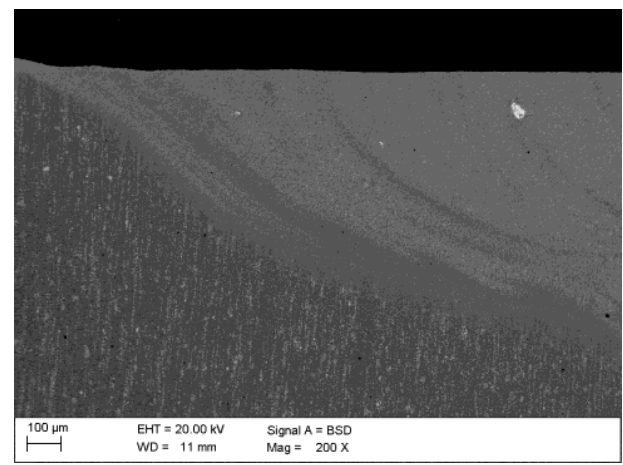

a

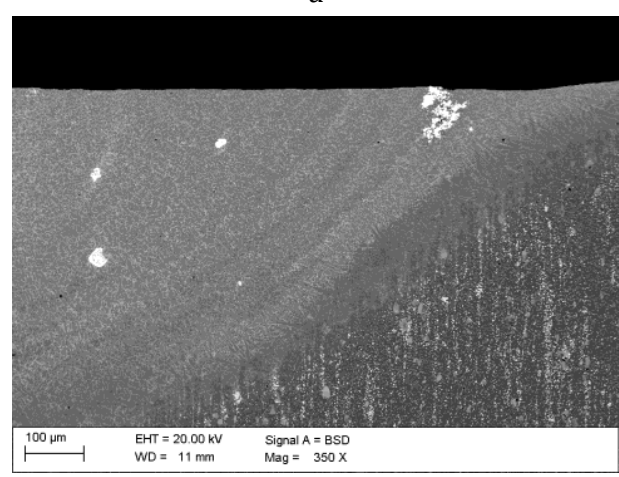

$\mathrm{b}$

Figure 4: Surface shapes and remelting depths of the high speed steel test piece transverse sections with the WC carbide particles with laser power values: a) $1.4 \mathrm{~kW}$, b) $2.1 \mathrm{~kW}$.

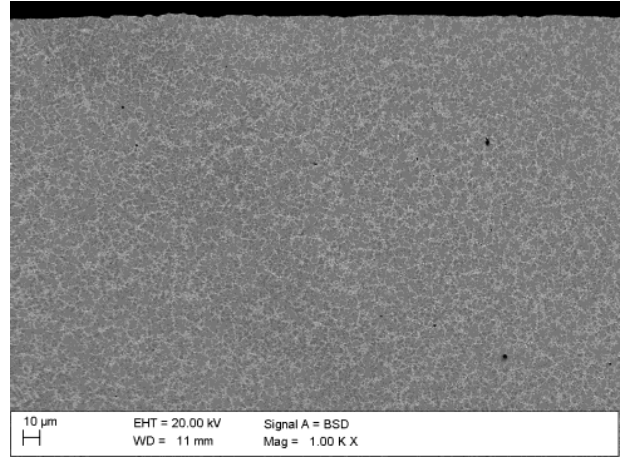

Figure 5: Central part of the steel surface after alloying with beam power- $1,4 \mathrm{~kW}$.

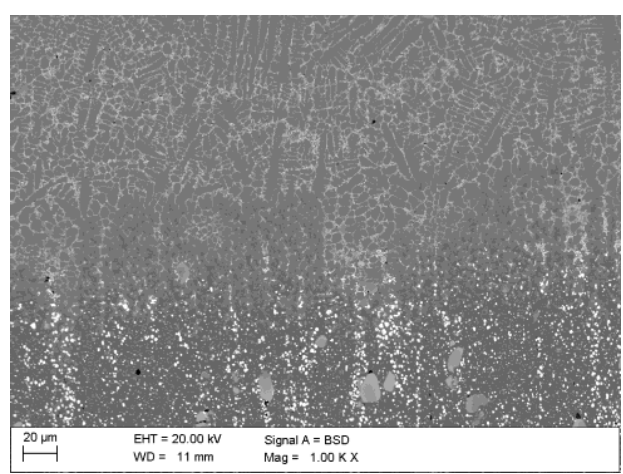

Figure 6: Boundary of the remelted steel surface layer after alloying with $\mathrm{WC}$, beam power-1,4 $\mathrm{kW}$.

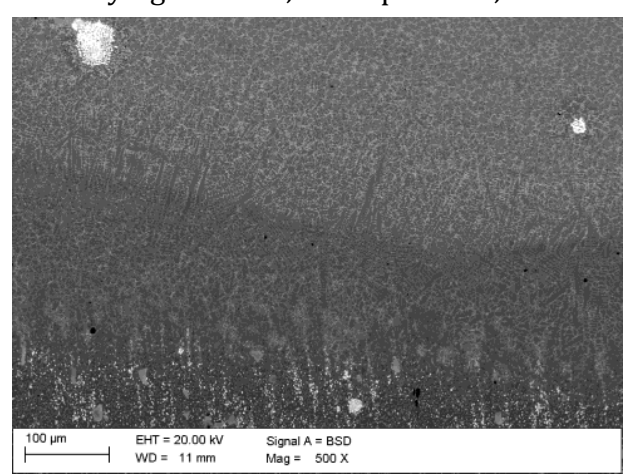

Figure 7: Alloying material in the steel surface layer after alloying with beam power-2,1 kW.

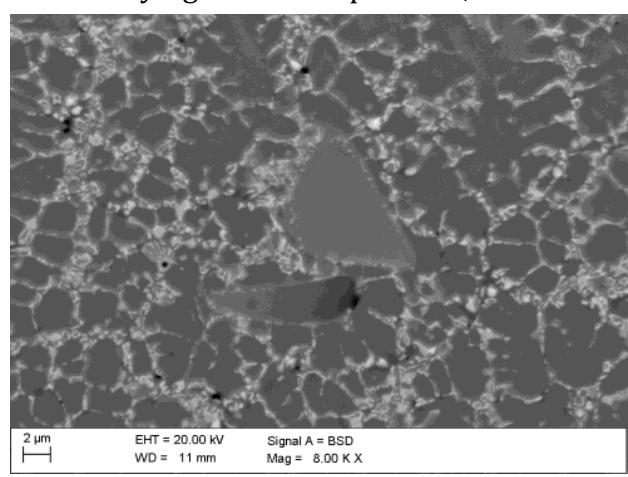

Figire 8: Fine eutectics and primary carbides in the alloyed zone of the steel surface layer after alloying, beam power-2,1 $\mathrm{kW}$. 


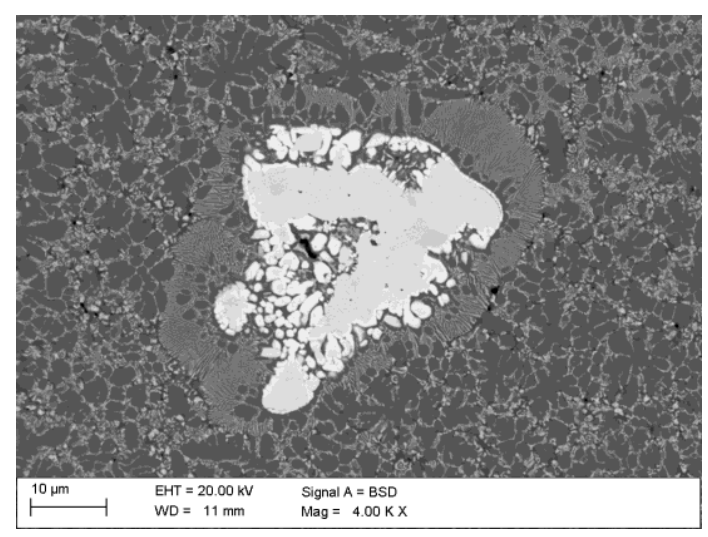

a

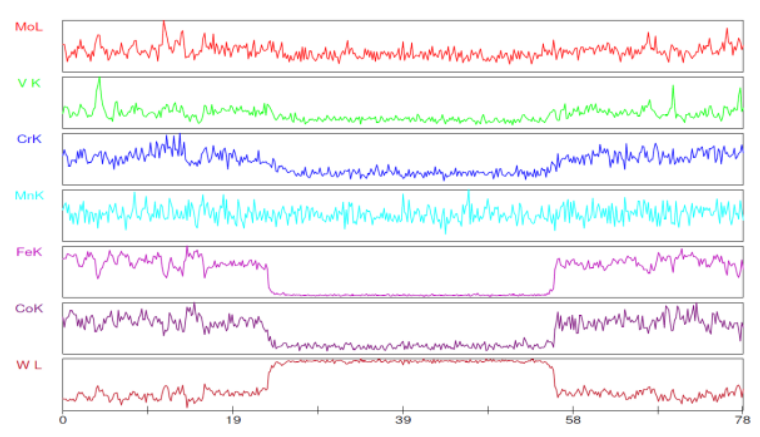

$\mathrm{b}$

Figure 9: Surface layer of the tool steel after alloying with the beam power-2,1 kW; a) SEM structure, b) linear analysis of the chemical composition changes.
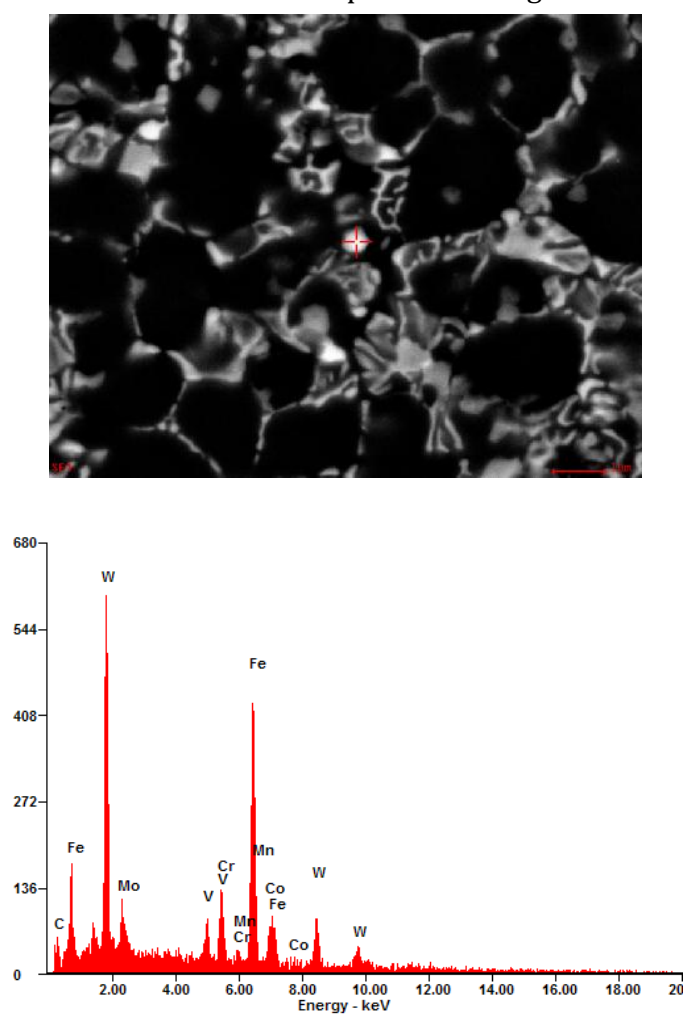

Figure 10: Microstructure of the tool steel (SEM) after WC alloying with the beam power $-1,4 \mathrm{~kW}$ and the plot of intensity versus energy dispersive Z OX-ray radiation, representing the pointwise $\mathrm{WC}$ carbide chemical composition analysis.
Metallographic examinations carried out on the light microscope and on the scanning microscope confirm that the structure of the material solidifying after laser remelting is diversified, which is dependant on the solidification rate of the investigated steels (Figs. 4-8). Occurrence of structure with big dendrites was revealed in areas on the boundary of the solid and liquid phases (Figs. 6-7). Protective gas impact on the molten steel surface plays a meaningful role in the remelting and alloying process, as it is flowing in the area of the developing surface layer and protecting steel in the liquid state from exposure to air and also participating in forming the crystallizing bead face and in transporting the alloying material remaining on the remelting surface. In case of alloying with the tungsten carbide powder, whose melting temperature is much higher than the steel melting temperature, penetration occurs of the undissolved tungsten carbide powder grains into the molten steel substrate (Fig. 7). Strong circulation of the molten metal occurs then, followed by sudden solidification when the laser beam has passed. Packing of the solidified crystals' bands is consistent with the schema of convection motions in the molten metal pool. Examinations of the chemical composition with the surface and pointwise methods reveal occurrences of the inundated WC particles in big conglomerates (Fig. 9). Analysis of the plots of linear change of chemical composition, obtained on the transverse surface layer microsections using the EDS system confirms presence of $\mathrm{Mo}, \mathrm{V}, \mathrm{Mn}, \mathrm{Cr}, \mathrm{W}, \mathrm{Fe}$ in the relevant zones of the surface layers. Moreover, using the X-ray microanalysis it was found out also that tungsten occurs not only in the form of conglomerates but also the remelted layer (Fig. 10). The chemical composition of the steel and conditions of its crystallisation affect phase transformations occurring during the colification and cooling processes. Due to the quick crystallisation of the hot-work tool steels after their laser remelting precipitation of the high-temperature ferrite from the liquid solution is observed most often. Next, the peritectic reaction occurs, which leads to origination of austenite. Concentrations of carbide and alloying elements, thatdepending on their portion - may precipitate directly from liquid, demonstrating clear segregation at the dendrite boundaries, have a significant effect on austenite origination. Moreover, WC tungsten carbide occurs in the steel after its alloying. Enrichment of the steel surface layer with tungsten is a consequence of using for alloying the commercially available tungsten carbide powder being a mixture of the WC and $\mathrm{W}_{2} \mathrm{C}$ interstitial carbides and pure tungsten. Tungsten introduced to steel is present in the remelted zone only; however, its concentration grows at the dendrite boundaries, like of other analysed carbide forming elements ( $\mathrm{Cr}, \mathrm{V}$ ). Grouping of the alloying elements was confirmed at dendrite boundaries in the area of the superfine eutectics occurring in the remelted zone due to fluctuation of the chemical composition, especially at the remelting bottom. Tungsten carbides and products of its high-temperature decomposition accumulate also at the remelting path edges and in flashes. This mechanism is most surely connected with the difference of the surface tensions of the molten steel and of the alloying material, as well as with the impact of the strong protective gas stream.

\section{Conclusion}

Alloying the investigated steel with tungsten carbide causes development of the surface layer, in which one can point out the fused zone, heat affected zone, and interface zones. Their thickness is closely connected with the fusion parameters, and thickness of the fused layer changes significantly along with 
the laser beam power increase. A fine-grained, dendritic structure was obtained in the fused zone, with the crystallographic orientation connected with the dynamical heat abstraction from the laser beam impact zone. Occurrences of the un-fused tungsten carbide grains were observed in the structure and the increased tungsten content compared to the native material, whose variable concentration is connected with the molten metal fluctuation in the pool during alloying.

\section{Acknowledgment}

This scientific work was financially supported by the Polish Ministry of Science and Higher Education as a research project no. N N507 471738 on the years 2010-2012.

\section{References}

[1] L.A. Dobrzański., M. Bonek., E. Hajduczek., A. Klimpel., A. Lisiecki.: Comparison of the structures of the hot-work tool steels laser modified surface layers, Journal of Materials Processing Technology, 164-165, 1014-1024, 2005.
[2] J. Kusiński.: Laser Applications in Materials Engineering, WN „Akapit”, Cracow, 2000 (in Polish).

[3] Lin Li.: The advances and characteristics of high-power diode laser materials processing, Optics and Lasers in Engineering 34, 231-253, 2000.

[4] M. Bonek, G. Matula, L.A. Dobrzanski: Effect of laser surface melting on structure and properties of a high speed tool steel, Advanced Materials Research, 2011, Vols. 291-294, 1365-1368.

[5] M. Bonek, L.A. Dobrzański: Characterization performance of laser melted commercial tool steels, Materials Science Forum, 2010, Vols. 654-656, 1848-1851.

[6] G. Matula, M. Bonek, L.A. Dobrzański: Comparison of Structure and Properties of Hard Coatings on Commercial Tool Materials Manufactured with the Pressureless Forming Method or Laser Treatment, Materials Science Forum, 2010, Vols. 638-642, 1830-1835. 